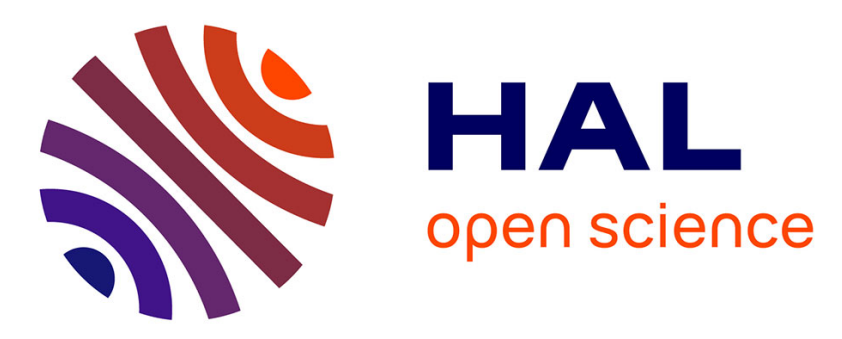

\title{
A microfluidic device to statistically determine the distribution of sickle red cell subpopulations using bioimpedance
}

Tieying Xu, Maria A Lizarralde-Iragorri, Jean Roman, Emile Martincic, Valentine Brousse, Olivier Français, Wassim El Nemer, Bruno Le Pioufle

\section{To cite this version:}

Tieying Xu, Maria A Lizarralde-Iragorri, Jean Roman, Emile Martincic, Valentine Brousse, et al.. A microfluidic device to statistically determine the distribution of sickle red cell subpopulations using bioimpedance. Transducers, 2021, on-line, France. hal-03260796

\section{HAL Id: hal-03260796 https://hal.science/hal-03260796}

Submitted on 15 Jun 2021

HAL is a multi-disciplinary open access archive for the deposit and dissemination of scientific research documents, whether they are published or not. The documents may come from teaching and research institutions in France or abroad, or from public or private research centers.
L'archive ouverte pluridisciplinaire HAL, est destinée au dépôt et à la diffusion de documents scientifiques de niveau recherche, publiés ou non, émanant des établissements d'enseignement et de recherche français ou étrangers, des laboratoires publics ou privés. 


\section{A MICROFLUIDIC DEVICE TO STATISTICALLY DETERMINE THE DISTRIBUTION OF SICKLE RED CELL SUBPOPULATIONS USING BIOIMPEDANCE}

Tieying $\mathrm{Xu}^{1}$, Maria A. Lizarralde-Iragorri ${ }^{2}$, Jean Roman ${ }^{1}$, Emile Martincic ${ }^{3}$, Valentine Brousse ${ }^{2}$, Olivier Français ${ }^{4}$, Wassim El Nemer ${ }^{2}$, and Bruno Le Pioufle ${ }^{5, *}$

${ }^{1}$ Université Paris-Saclay, ENS Paris-Saclay, CNRS, Institut d'Alembert, Gif sur Yvette, FRANCE ${ }^{2}$ Université de Paris, UMR_S1134, BIGR, Inserm, Paris, FRANCE

${ }^{3} \mathrm{C} 2 \mathrm{~N}, \mathrm{CNRS}$, Université Paris-Saclay, Palaiseau, FRANCE

${ }^{4}$ ESYCOM, Université Gustave Eiffel, CNRS, ESIEE Paris, Marne-la-Vallée, FRANCE and

${ }^{5}$ Université Paris-Saclay, ENS Paris-Saclay, CNRS, Institut d'Alembert, LUMIN, Gif sur Yvette, FRANCE

\begin{abstract}
Bioimpedance measurements using microfluidic systems play an increasingly important role in cell analysis. In this paper, a microfluidic device mimicking the vasculature, in particular blood microcapillaries, and equipped with electrodes for bioimpedance sensing is described. Red blood cells, from patients suffering from sickle cell disease, were analyzed and discriminated in this device according to the physical parameters. The statistical position of different subpopulations on the Gaussian distribution of the whole sickle cell population was analyzed. A discrimination between sickle cell subpopulations, related to different density states, was achieved.
\end{abstract}

\section{KEYWORDS}

Sickle cell subpopulations, Bioimpedance, Microfluidic, Statistical single cell analysis

\section{INTRODUCTION}

Thanks to their capability to deform, red blood cells (RBCs, diameter of $8 \mu \mathrm{m}$, thickness of $2 \mu \mathrm{m}$ ) circulate in the blood microcapillaries network and play a crucial role in the exchange of oxygen and carbon dioxide [1], which maintains the function of human organs.

However, several genetic disorders may affect the RBC functions. Sickle cell disease (SCD) is characterized by the expression of a mutated hemoglobin that polymerizes under hypoxic conditions driving RBC sickling [2]. RBC shape changes from biconcave to sickle shape, which induces vaso-occlusive crises and decreases the level of oxygen supplied to the organs, leading to a loss of organ function. This disease touches millions of people in the world.

SCD RBCs are very heterogeneous in shape and morphology because of differential sickling and hydration state. To analyze the SCD RBC subpopulations, a microfluidic device is developed which reproduces the blood flow network. It is equipped with electrodes for electrical recording and bioimpedance analysis. Thanks to the electrical monitoring, physical parameters like the transit time and the blockade amplitude in microfluidic restrictions mimicking the blood microcapillary could be extracted and statistically analyzed.

SCD RBC subpopulations were discriminated by the analysis of the data associated to transit electrical flow profile (transit time and blockade amplitude). That system might be a promising approach to determine the distribution of RBCs in patients and potentially predict disease severity or impact of treatments.

\section{THEORY}

Bioimpedance is a non-invasive method for analyzing cellular electrical parameters without molecular labeling and does not require to optically visualize the cell.

The bioimpedance relies on the dielectric properties of the cells and of the medium, and expresses as follows, using the Maxwell's heterogeneous model [3]:

$$
Z_{\text {mix }}(\omega)=\frac{D}{S} \frac{1}{\sigma_{\text {mix }}+i \omega \varepsilon_{\text {mix }}}=\frac{D}{S} \frac{1}{i \omega \varepsilon^{*}{ }_{\text {mix }}}
$$

Where $\mathrm{D}$ represents the equivalent distance between the electrodes (face to face), $\mathrm{S}$ represents their surface, $\sigma_{\text {mix }}$ corresponds to the conductivity of the mixture (between medium and cells) and $\varepsilon_{\text {mix }}$ is its permittivity. $\varepsilon^{*}{ }_{\text {mix }}=$ $\varepsilon_{\text {mix }}-\mathrm{i} \frac{\sigma_{\mathrm{mix}}}{\omega}$ represents the complex permittivity of the system.

In case of a cell, the real part represents the cellular dielectric polarization (the cell permittivity $\left.\varepsilon_{\text {cell }}\right)$ and the imaginary part is related to the conduction losses $\left(\sigma_{\text {cell }}\right)$. The cell being a heterogeneous living object, its complex permittivity depends on the cytoplasmic membrane and cell content. The permittivity of a spherical cell could be approximated by the single shell model [4]. The cell content dielectric properties are represented by $\sigma_{\text {in }}$ and $\varepsilon_{\text {in }}$. And those of the membrane are represented by $\sigma_{\text {memb }}$ and $\varepsilon_{\text {memb. We have: }}$

$$
\varepsilon_{\text {cell }}^{*}=\varepsilon^{*}{ }_{\text {memb }}\left[\frac{\left(\frac{R}{R-e}\right)^{3}+2\left(\frac{\varepsilon^{*} \text { in }-\varepsilon^{*} \text { memb }}{\varepsilon^{*} \text { in }+2 \varepsilon^{*} \text { memb }}\right)}{\left(\frac{R}{R-e}\right)^{3}-\left(\frac{\varepsilon^{*} \text { in } \varepsilon^{*} \text { memb }}{\varepsilon^{*} \text { in }+2 \varepsilon^{*} \text { memb }}\right)}\right]
$$

Where $\mathrm{R}$ represents the radius of the cell and $\mathrm{e}$ the thickness of the membrane.

At low frequencies, the cell membrane is predominant. The permittivity of the cell can be approximated to: $\varepsilon^{*}{ }_{\text {cell }}=\frac{\mathrm{R}}{\mathrm{e}} \varepsilon^{*}{ }_{\text {memb }}$.

The complex permittivity of the mixture between the electrodes expresses:

$$
\varepsilon_{\text {mix }}^{*}=\varepsilon^{*} \frac{1+2 \Phi f_{C M}}{1-2 \Phi f_{C M}}
$$

Where $\Phi$ is the volume fraction between the cell and the medium. $\mathrm{f}_{\mathrm{CM}}$ represents the Clausius-Mossotti factor: 


$$
f_{C M}=\frac{\varepsilon_{c e l l}^{*}-\varepsilon_{m}^{*}}{\varepsilon_{c e l l}^{*}+2 \varepsilon_{m}^{*}}
$$

Depending on the frequency range of the excitation signal, the impedance spectrum of the miniaturized system filled by cells suspension can be obtained. The sensitivity of this method necessarily depends on the distance D between the electrodes as well as on the volume fraction $\Phi$.

The effect of the double layer capacitance at the interface between the electrodes and the medium need also to be taken into account. This layer can vary from a few nanometers to ten nanometers [5]. Its capacitance expresses $C_{D L}=C_{S} S$ (with $C_{S}$ the surface capacity of the double layer effect and $\mathrm{S}$ the surface of the considered electrode). This adds to the system an impedance:

$$
Z_{D L}(\omega)=\frac{1}{j \omega C_{D L}}
$$

Black platinum electrodes present a double layer surface capacitance $C_{s}$ advantageously high, as $0.5 \mathrm{~F} . \mathrm{m}^{-2}$ [6]. This value can be increased by increasing the roughness of the electrode in order to decrease the associated impedance and make its effect negligible.

Finally, optimized frequency was chosen in the frequency range where these two cases could be distinguished by the difference of the impedance modulus: with and without RBC in the microcapillary. Under such frequency, impedance measurement in real time could be achieved (See Figure 1.A. and B.).

\section{EXPERIMENTAL}

The microfluidic device, dedicated to the sickle cell analysis, was built in two parts: the microfluidic capillaries network part and the bioimpedance monitoring part.

A Polydimethylsiloxane (PDMS) chip containing microfluidic network was manufactured by soft lithography method. The microcapillary has a symmetric structure: a $30 \mu \mathrm{m}$ long thin capillary with rectangular section (width $=5 \mu \mathrm{m}$, thickness $=2 \mu \mathrm{m}$ ), followed by a slightly wider section channel (width $=10 \mu \mathrm{m}$, same thickness) and connected to a wide channel (width $=20 \mu \mathrm{m}$, same thickness).

The PDMS subpart was placed manually above the quartz substrate containing gold electrodes $(\mathrm{Cr} 20 \mathrm{~nm} / \mathrm{Au}$ $200 \mathrm{~nm})$. The sickle red blood cells suspension sample (2\% hematocrit) was inserted at the inlet of the microcapillary network. The PDMS subpart was maintained on the substrate thanks to the depressurization (-250mbar) applied during the experiment at the outlet of the microcapillaries network, inducing the RBC circulation within the microchannels.

To realize the electrical detection, a portable Analog Discovery multifonction hardware was used to generate the electrical excitation and record the feedback signal. The sinusoidal voltage signal was applied to the microcapillary via gold electrodes and the detected current in the biological sample was converted to a voltage thanks to an AD847J based transimpedance amplifier. Full signal was digitalized (sampling frequency $500 \mathrm{kHz}$ ). Data processing based on numerical synchronous detection with a dedicated algorithm (Igor Pro) is then achieved to extract physical parameters (transit time, blockade amplitude).
For calibration, imaging of the red blood cell transit in the microcapillary was simultaneously performed thanks to a high-speed Phantom MIRO M 3205 camera mounted on an inverted microscope (Zeiss AxioObserver Z1 microscope).

Thanks to a Percoll fraction (See Figure 2.A.) [7], sickle cells were classified into 3 types (or subpopulations): cells of low density (LD SCD RBCs), of medium density (D SCD RBCs) and of high density (HD SCD RBCs). RBCs were conserved in Cellstab solution and diluted into the conductive solution $(1.26 \mathrm{~S} / \mathrm{m})$ to obtain $2 \%$ RBCs suspension for the bioimpedance monitoring.

\section{RESULTS AND DISCUSSION}

First, the control sample (healthy red blood cells) was introduced in the device. With our conditions, the electrical recording of 1696 RBCs showed a single mean transit time equal to $7.13 \mathrm{~ms}$ and a single mean blockade amplitude equal to $1.76 \times 10^{-3} \mathrm{~V}$. For SCD RBCs, multiple peaks appeared on the histogram of the transit time (See Figure 2.A., $7.54 \mathrm{~ms}$ and $13.26 \mathrm{~ms}$, for $1298 \mathrm{RBCs}$ ) and the blockade amplitude (See Figure 2.B., $1.12 \times 10^{-3} \mathrm{~V}, 1.99 \times 10^{-}$ ${ }^{3} \mathrm{~V}$ and $2.09 \times 10^{-3} \mathrm{~V}$, for 1298 cells) [8]. To understand this phenomenon, an analysis of isolated subpopulations was established.

For LD, D and HD SCD RBC subpopulations, decreasing values of the mean transit time were obtained (Figure 3.A., B. and C., LD SCD RBCs: 8.3ms, D SCD RBCs: $8.2 \mathrm{~ms}$, HD SCD RBCs: 7.7ms), indicating that LD SCD RBCs take longer time to pass through the microcapillary restriction.

Our hypothesis is that HD RBCs have a smaller contact surface with the wall of the microcapillary than LD RBCs, leading to a shorter transit time. Even though the cell rigidity increases from LD to D and to HD SCD RBCs, the effect of the contact surface is preponderant.

Considering the blockade amplitude, a decrease was also observed from LD to D and to HD SCD RBCs (See Figure 4.A., B. and C., LD SCD RBCs: $1.9 \times 10^{-3} \mathrm{~V}$, D SCD RBCs: $1.77 \times 10^{-3} \mathrm{~V}$, HD SCD RBCs: $1.65 \times 10^{-3} \mathrm{~V}$ ).

SCD RBC subpopulations are identified with this hypothesis on the histogram of the blockade amplitude (See Figure 2.B.):

i) HD SCD RBCs have low blockade amplitude due to their sickle shape, which results in a small contact surface.

ii) LD SCD RBCs have high blockade amplitude because of the appearance of the reticulocytes, which are large and light, bring a large contact surface.

iii) D SCD RBCs have a blockade amplitude close to the control RBCs behavior.

At the same time, thanks to the transparency of the microfluidic device, the imaging of the cell transit was possible during the experiment. The cell shape corresponding to each SCD subpopulation is shown in Figure 2.B.

\section{CONCLUSION}

The cell bioimpedance monitoring within biomimicking microcapillary network brings the new possibility to achieve a statistical analysis of the distribution of SCD RBCs, which may offer new tools in 
patients management.

Higher density of sickle cells leads to lower transit time within the microcapillary restriction, as well as a decreasing blockade amplitude.

This approach is very promising for future microfluidic systems for the follow-up of SCD patients over time and during treatments. Further analysis, including the scatter plot of physical parameters, is possible. Such approach characterizing cellular abnormalities based on bioimpedance might be useful for future biomedical applications.
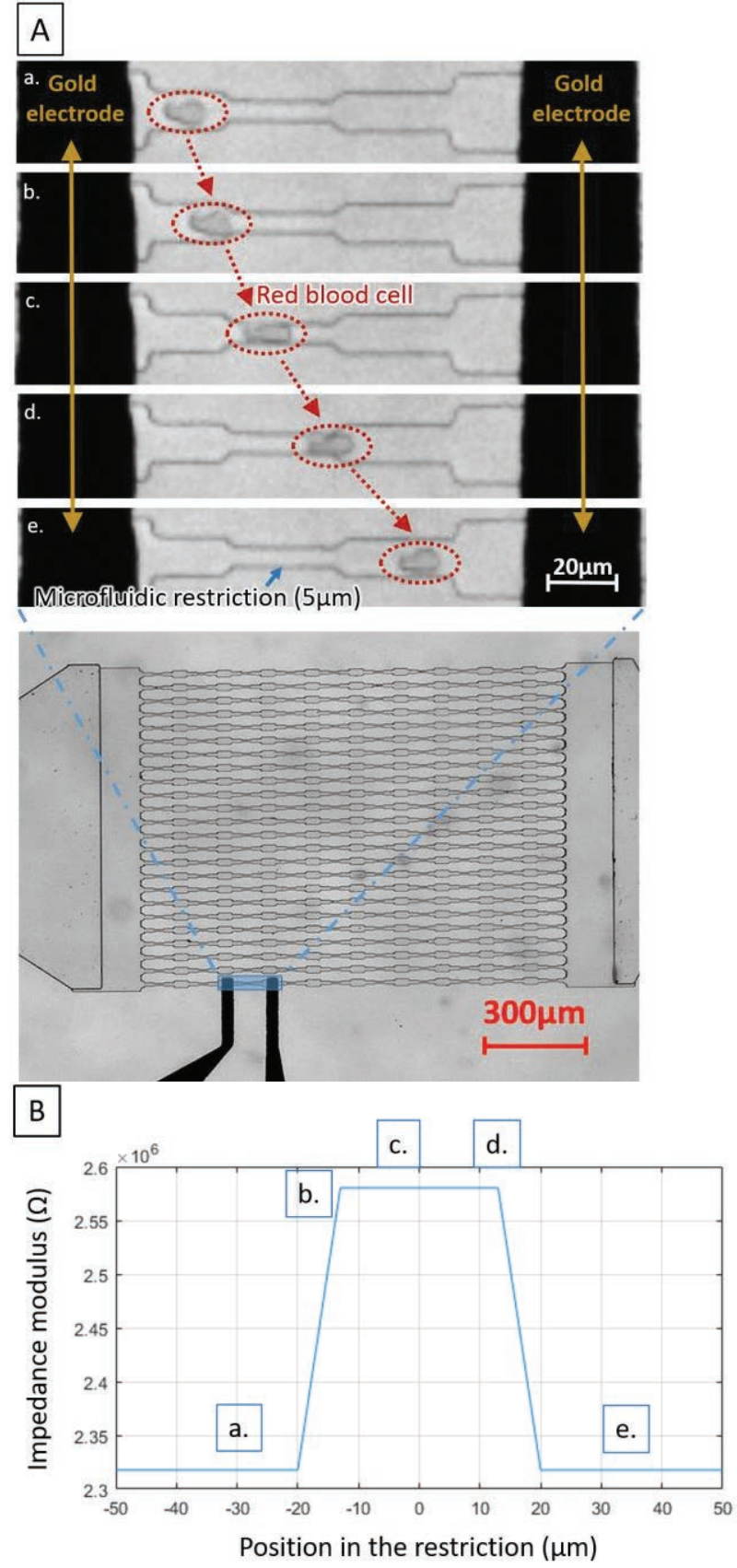

Figure 1: A. Red blood cell transit in the third restriction of the external branch of the matrix $(24 \times 10)$; B. Impedance modulus time dependence, due to the red blood cell transit in the restriction.
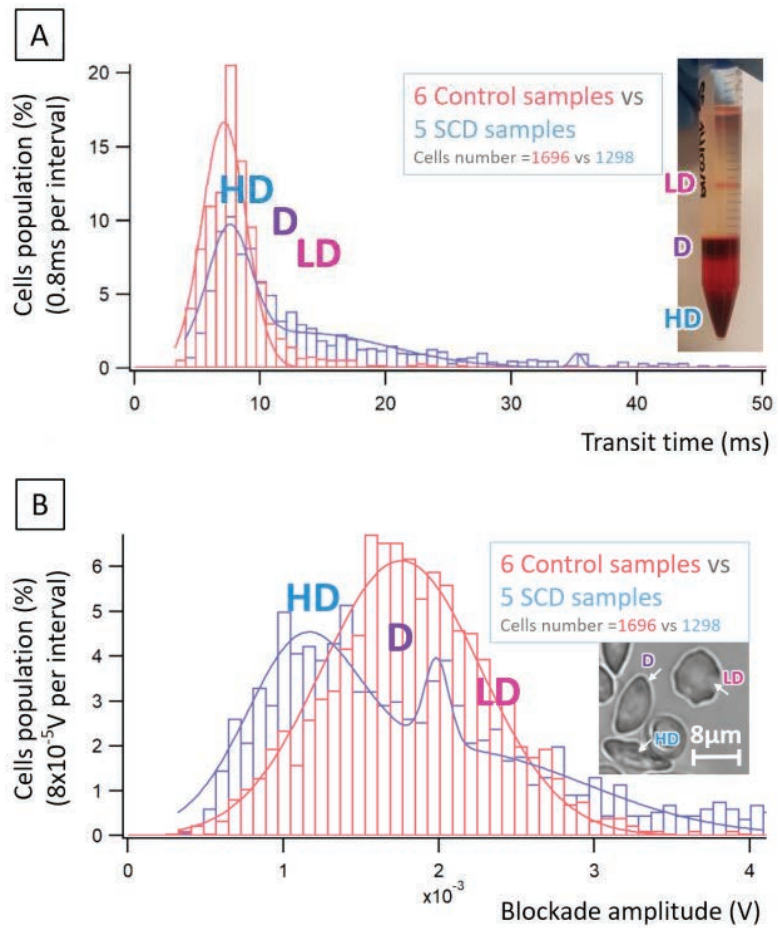

Figure 2: A. Gaussian distribution fitted with histogram of the transit time for normal RBCs (1696cells) and whole SCD RBCs (1298cells) populations. Percoll fraction result is at the right side of the Figure A; B. Gaussian distribution fitted with histogram of the blockade amplitude for normal RBCs (1696cells) and whole SCD RBCs (1298cells) populations. The position of $L D, D$ and $H D$ SCD subpopulations is included. Corresponding cell shapes are shown at the right side of the Figure $B$.
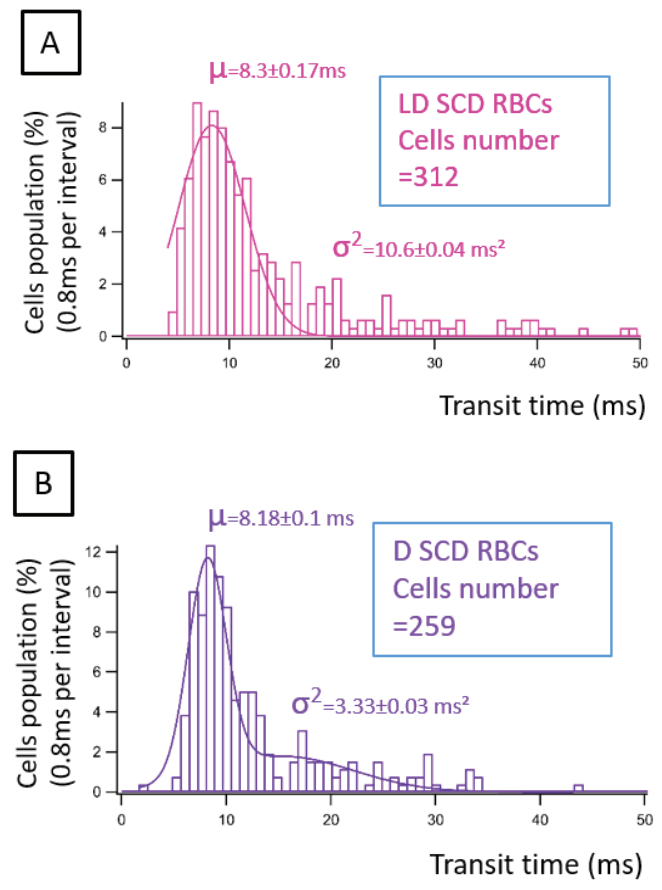


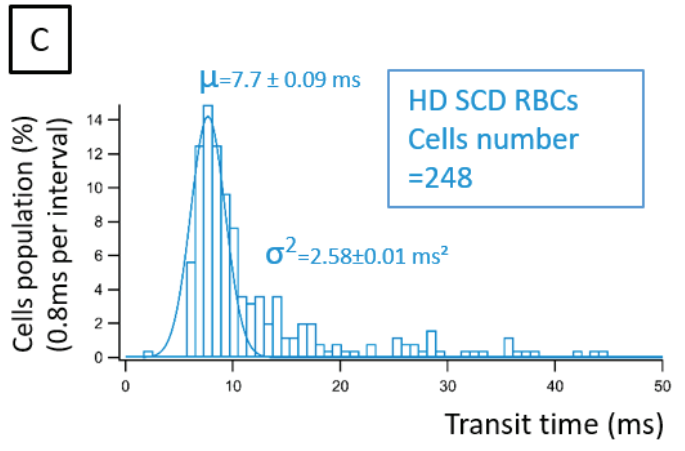

Figure 3: Gaussian distribution fitted with histogram of the transit time. A. Mean transit time and its variation for $L D$ SCD RBCs subpopulation (cell number=312); B. Mean transit time and its variation for $D$ SCD RBCs subpopulation (cell number=259); C. Mean transit time and its variation for HD SCD RBCs subpopulation (cell number $=248$ ).
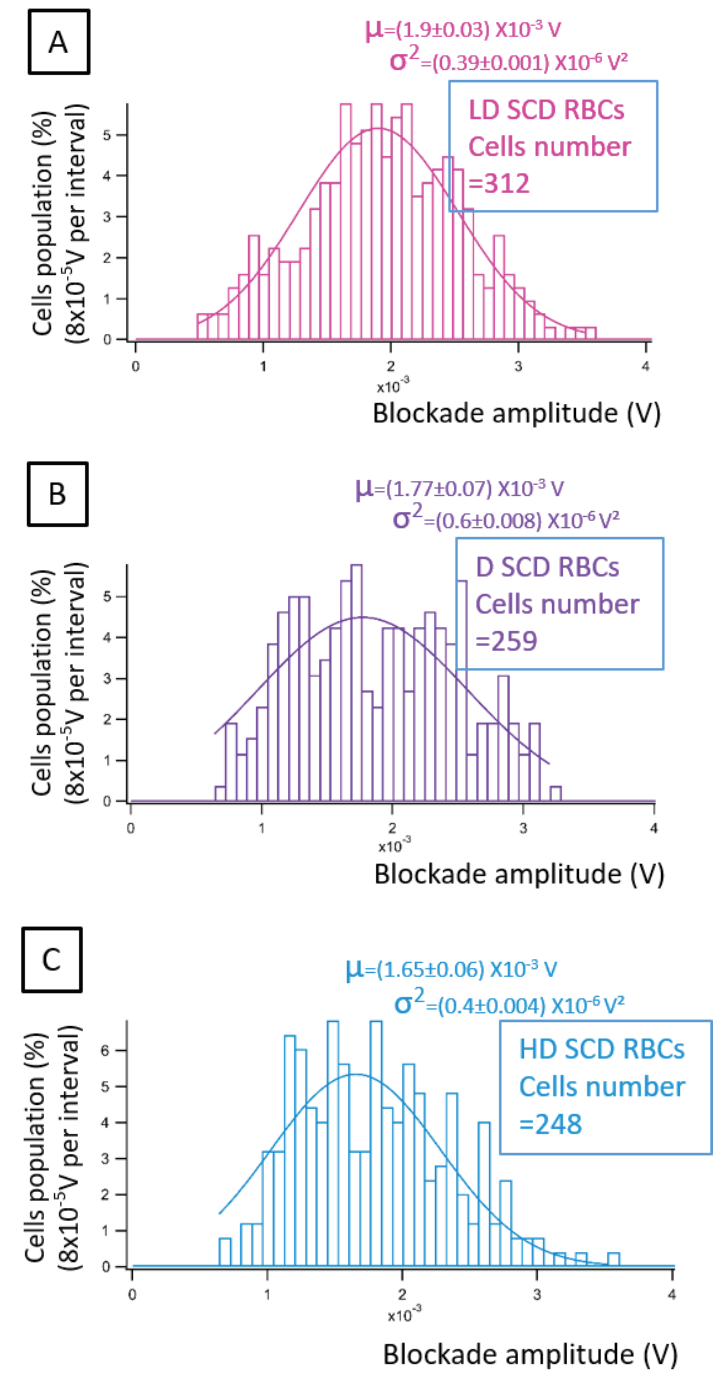

Figure 4: Gaussian distribution fitted with histogram of the blockade amplitude. A. Mean blockade amplitude and its variation for LD SCD RBCs subpopulation (cell number=312); B. Mean blockade amplitude and its variation for $D$ SCD RBCs subpopulation (cell number=259); C. Mean blockade amplitude and its variation for HD SCD RBCs subpopulation (cell number=248).

Table 1: Mean value of the transit time and the blockade amplitude for each SCD subpopulation.

\begin{tabular}{|l|c|c|}
\hline Type & $\begin{array}{c}\text { Transit time } \\
\text { (ms) }\end{array}$ & $\begin{array}{c}\text { Blockade } \\
\text { amplitude }\left(\mathbf{1 0}^{-3} \mathbf{V}\right)\end{array}$ \\
\hline LD & $8.3 \pm 0.17$ & $1.9 \pm 0.03$ \\
\hline D & $8.2 \pm 0.1$ & $1.77 \pm 0.07$ \\
\hline HD & $7.7 \pm 0.09$ & $1.65 \pm 0.06$ \\
\hline
\end{tabular}

\section{ACKNOWLEDGEMENTS}

The authors acknowledge the Labex LaSIPS (ANR10-LABX-0040-Lasips), ANR Epsilomics (ANR17-CE090044-02), and the "Ecole Doctorale EOBE" of Université Paris-Saclay, the "Institut d'Alembert" and the "CNRS" for project fundings.

\section{REFERENCES}

[1] C. D. E. Verdier, "2,3-Diphosphoglycerate and respiratory function of hemoglobin.," pp. 613617, 1972.

[2] L. Pauling, H. A. Itano, S. J. Singer, and I. C. Wells, "Sickle Cell Anemia, a Molecular Disease,” Science (80-. )., vol. 110, no. 2865, pp. 543-548, Nov. 1949.

[3] A. Valero, T. Braschler, and P. Renaud, "A unified approach to dielectric single cell analysis: Impedance and dielectrophoretic force spectroscopy," Lab Chip, vol. 10, no. 17, p. 2216, 2010.

[4] Y. Huang, R. Holzel, R. Pethig, and X.-B. Wang, "Differences in the AC electrodynamics of viable and non-viable yeast cells determined through combined dielectrophoresis and electrorotation studies," Phys. Med. Biol., vol. 37, no. 7, pp. 1499-1517, Jul. 1992.

[5] J. N. Israelachvili and G. E. Adams, "Measurement of forces between two mica surfaces in aqueous electrolyte solutions in the range 0-100 nm," J. Chem. Soc. Faraday Trans. 1 Phys. Chem. Condens. Phases, vol. 74, pp. 9751001, 1978.

[6] S. Grimnes and Ø. G. Martinsen, "GEOMETRICAL ANALYSIS," in Bioimpedance and Bioelectricity Basics, Elsevier, 2008, pp. 161-204.

[7] M. Fabry et al., "Dense cells in sickle cell anemia: the effects of gene interaction," Blood, vol. 64, no. 5, pp. 1042-1046, Nov. 1984.

[8] T. Xu et al., "Characterization of red blood cell microcirculatory parameters using a bioimpedance microfluidic device," Sci. Rep., vol. 10, no. 1, p. 9869, Dec. 2020.

\section{CONTACT}

* B. Le Pioufle: bruno.le-pioufle@ens-paris-saclay.fr 